\title{
PERÍODO CRÍTICO DE COMPETIÇÃO ENTRE COMUNIDADES DE PLANTAS DANINHAS E O ALGODOEIRO (Gossypium hirsutum L.) NO ESTADO DE MINAS GERAIS
}

\author{
J.P. del C. LACA-BUENDIA*, A.A.C.PURCINO** \\ J.C.V.PENNA ** \& L. FERREIRA** \\ * Eng. ${ }^{\circ}$ Agr. ${ }^{\circ}$, Coordenador do Projeto Algodão - \\ EPAMMIG. 30.000 - Belo Horizonte, MG \\ ** Eng. ${ }^{\circ} \mathrm{S}$ Agr. ${ }^{\circ}$ s, Pesquis adores da EPAMIG. \\ 38.100 - Uberaba, MG \\ Trabalho parcialmente apresentado no III Con- \\ gresso de la Asociación Latino Americana de \\ Malezas (ALAM) e VIII Reunión de Malezas y \\ su Control (ASAM). Mar del Plata-Argentina, \\ 1976. \\ Recebido para publicação em 14.09.79.
}

\section{RESUMO}

Foram instalados nove ensaios no período de 1973 a 1976 em solos LVA, LE e LR de três localidades do Triângulo e duas no Norte do Estado de Minas Gerais, Brasil, a fim de se estudar as épocas críticas de competição de plantas daninhas com o algodoeiro (Gossypium hirsutum L.). Os tratamentos foram: capinas até $2,4,6,8$ primeiras semanas e durante todo o ciclo; e capinas após 2 , 4, 6, 8 primeiras semanas e todo o ciclo sem capinas. Os resultados mostraram que a competição das plantas daninhas, quando não controladas, com a cultura, provocou $90,22 \%$ de perda na produção no Triângulo Mineiro e $70,73 \%$ no Norte de Minas. Em relação à testemunha, mantida livre de competição durante todo o ciclo, o melhor rendimento foi obtido quando se manteve a cultura livre de competição durante seis: emanas após a emergência, no Triâgulo Mineiro, e durante oito semanas, no Norte de Minas. Não houve, entretanto, diferença significativa entre os tratamentos com 4, 6, 8 semanas e também com todo o ciclo sem competição, tanto no Triângulo quanto no Norte do Estado.

UNITERMOS: Plantas daninhas, competição, algodão.

\section{SUMMARY}

THE CRITICAL PERIOD OF COMPETITION BETWEEN WEED COMMUNITIES AND COTTON (Gossypium hirsutum L.) IN THE STATE OF MINAS GERAIS.

Nine tests were made from 1973 up to 1976 on different soil types in five localities (three in the Triângulo Mineiro and two in the Northern Region of Minas Gerais State, Brazil) to Study the critical periods of weed competition with cotton (Gossypium hirsutum L.). The treatments consisted of: weed free during the first $2,4,6,8$ weeks and all the cycle; and competition during the first 2, 4, 6,8 weeks and all the cycle. The results showed yield losses of $90,22 \%$ in the Triângulo Mineiro and $70,73 \%$ in the Northern Region when weed were always present. Compared to the check free of weeds during all the cycle, the best yield was obtained when cotton was kept free of weeds during the first six weeks after emergence in the Triângulo Mineiro as well as during the first eight weeks in the Northern Region. However, there was no difference among the treatments consisting of 4 , 6,8 weeks, and all the cycle without weed competition for both regions studied.

KEYWORDS: Weeds, weed competition, Cotton.

\section{INT RODUÇÃO}

A competição com plantas daninhas é um dos fatores que mais afetam a produtividade da cultura algodoeira, ocasionando diminuição no rendimento e na qualidade do produto e aumentando o custo de produção.

A competição por luz, água e nutrientes é maior quando as plantas daninhas se tornam dominantes. Sombreiam o algodoeiro, removem mais água e grande quantidade de nutrientes do solo. Em anos de baixa precipitação pluviométrica elas podem retirar de 3 a 
4 vezes mais $\mathrm{N}, \mathrm{K}$ e $\mathrm{Mg}$ do que a cultura sem competição, não se notando diferença para $\mathrm{P}$, Ca e $\mathrm{Zn}$. Em condições normais de precipitação, removem de 2 a 3 vezes mais $K$ e $Z n$ que uma cultura limpa, sem alterar as quantidades de $\mathrm{N}$, $\mathrm{P}$, Ca e Mg (15).

Estudos feitos na Colômbia identificaram ser de 20 a 40 dias de idade da cultura, o período crítico de competição das plantas daninhas com o algodoeiro (7 e 12). No México, até 120 dias (11). Nos EEUU aproximadamente nas 8 semanas iniciais (3). Em condições de baixa pluviosidade o período crítico foi de 2 a 4 semanas, enquanto que com chuvas normais são necessárias 6 a 8 semanas sem competição (15). Nas Filipinas, as capinas após a segunda semana não tiveram efeito significativo no rendimento (5).

Em São Paulo. as plantas daninhas afetaram os rendimentos nos primeiros 20 a 40 dias em Campinas, Tietê e Santa Bárbara do Oeste (2 e 6). Beltrão et al. (1) observaram redução drástica no número e tamanho das folhas, diminuindo assim o índice de área foliar da cultura.

Rogers et al. (13) estudaram a influência de espaçamento entre fileiras sobre plantas daninhas, observando que quando as fileiras eram mais fechadas $(53 \mathrm{~cm})$, o rendimento máximo foi obtido quando a cultura permaneceu no limpo durante as 6 primeiras semanas. Com fileiras mais espaçadas $(106 \mathrm{~cm})$, o periodo necessário para um ren- dimento máximo foi de 10 a 14 semanas sem competição.

Um controle econômico deve ser baseado no periodo crítico de competição entre as plantas daninhas e a cultura. Esta competição varia em função do ambiente, cultura, espécie e número de plantas daninhas. Conhecendo-se a interação destes fatores, pode-se estabelecer um programa para o seu controle.

\section{MATERIAIS E MÉTODOS}

Nove ensaios foram instalados nas regiões do Triângulo Mineiro, em Latos solo Roxo (Capinópolis - Fazenda São José, em 1974 e 1975; Cachoeira Dourada - Fazenda Lagoa Dourada, em 1975 e Centralina - Fazenda Sumidouro, em 1976) e Norte de Minas em Latossolo vermelhoamarelo (Porteirinha - Fazenda São Miguel de Gorutuba, 1973, 1974, 1975 e 1976) e Latossolo vermelho-escuro (Jafba-Campo Experimental de Rio Verde, em 1976) cujas análises químicas encontram-se no quadro 1.

As cultivares utilizadas foram IAC 13-1 (Triângulo Mineiro) e IAC 13-1 e "Minas Dona Beja> (Norte de Minas).

O delineamento experimental usado foi blocos casualizados com 10 tratamentos, repetidos 4 vezes. As parcelas constavam de 5 fileiras com 5 metros de comprimento, espacadas de $1, \mathrm{OOm}$ (Triângulo) e $0,80 \mathrm{~m}$ (Norte de Minas), perfazendo uma ârea de $20 \mathrm{~m}^{2}$ (Triàngulo) e $16 \mathrm{~m}^{2}$ (Norte de Minas) sendo a área útil de $10 \mathrm{~m}^{2}$ (Triângulo) e $8 \mathrm{~m}^{2}$ (Norte de Minas).

O plantio foi realizado durante a segunda quinzena do mês de outubro para o Triâ ngulo e entre a segunda quinzena de outubro e primeira quinzena de novembro para o Norte de Minas. As sementes foram colocadas, de maneira seguida, no sulco deixando-se cair 30 sementes por metro de fileira. A emergência ocorreu após 8 a 15 dias do plantio. O desbaste foi realizado 20 a 25 dias após emergência deixando-se 5 a 7 plantas por metro de fileira.

Quadro 1 - Resultados das análises químicas dos solos, onde foram instalados os ensaios

\begin{tabular}{|c|c|c|c|c|c|}
\hline Localidades e anos & $\underset{\text { Âgua }}{\mathbf{p H}}$ & $\underset{\text { eq.mg./100 cc }}{\mathrm{Al}^{3+}}$ & $\begin{array}{l}\mathrm{Ca}^{2+}+\mathrm{Mg}^{2+} \\
\text { eq.mg. } / 100 \mathrm{cc}\end{array}$ & $\underset{\mathbf{p p m}}{\mathbf{K}^{+}}$ & $\underset{\mathrm{ppm}}{\mathbf{P}}$ \\
\hline $\begin{array}{l}\text { Triângulo Mineiro: } \\
\text { - Capinópolis - 74/75 } \\
\text { - Capinópolis - 75/76 } \\
\text { - C. Dourada - 75/76 } \\
\text { - Centralina - 76/77 }\end{array}$ & $\begin{array}{l}6,0 \\
5,9 \\
4,9 \\
5,1\end{array}$ & $\begin{array}{l}0,01 \\
0,1 \\
0,2 \\
0,2\end{array}$ & $\begin{array}{r}10,0 \\
9,3 \\
2,4 \\
2,1\end{array}$ & $\begin{array}{r}>135 \\
132 \\
36 \\
80\end{array}$ & $\begin{array}{r}59 \\
50 \\
8 \\
13\end{array}$ \\
\hline $\begin{array}{l}\text { Norte de Minas: } \\
\text { - Porteirinha - } 73 / 74 \\
\text { - Porteirinha - 74/75 } \\
\text { - Porteirinha - 75/76 } \\
\text { - Porteirinha - 76/77 } \\
\text { - Jaiba - 76/77 }\end{array}$ & $\begin{array}{l}6,2 \\
6,0 \\
6,4 \\
6,1 \\
5,0\end{array}$ & $\begin{array}{l}- \\
\overline{0} \\
0,05 \\
0,1 \\
0,2\end{array}$ & $\begin{array}{l}5,8 \\
6,3 \\
4,1 \\
4,6 \\
6,6\end{array}$ & $\begin{array}{r}>135 \\
>135 \\
134 \\
146 \\
136\end{array}$ & $\begin{array}{r}6 \\
20 \\
14 \\
17 \\
4\end{array}$ \\
\hline
\end{tabular}


A adubação foi feita no momento do plantio, aplicando-se $50 \mathrm{~kg} /$ ha de sulfato de amõnio, $600 \mathrm{~kg}$ de superfosfato simples e $40 \mathrm{~kg}$ de cloreto de potássio (Norte de Minas); e, $60 \mathrm{~kg}$ de cloreto de potássio no Triângulo Mineiro. Aos 35-40 dias após a emergência, foi realizada uma adubação em cobertura com $100 \mathrm{~kg} /$ ha de sulfato de amónio, colocado $0,15 \mathrm{~m}$ ao lado das plantas.

Os ensaios foram mantidos livres de ataque de pragas, fazendo-se de 7 a 15 tratamentos fitossanitários conforme a região onde foram conduzidos.

Os tratamentos foram os seguintes:

1. Testemunha com capina, livre de plantas daninhas até a colheita;

2. Livre de plantas daninhas durante as 2 primeiras semanas e, depois, com plantas daninhas até a colheita;

3. Livre de plantas daninhas, durante as 4 primeiras semanas e, depois, com plantas daninhas até a colheita;

4. Livre de plantas daninhas durante as 6 primeiras semanas e, depois, com plantas daninhas até a colheita;

5. Livre de plantas daninhas durante as 8 primeiras semanas e, depois, com plantas daninhas até a colheita;

6. Testemunha sem capina, até a colheita;

7. Com plantas daninhas durante as 2 primeiras semanas e, depois, completamente livre de plantas daninhas até a colheita;

8. Com plantas daninhas durante as 4 primeiras semanas e, depois, completamente livre de plantas daninhas até a colheita;

9. Com plantas daninhas durante as 6 primeiras semanas e, depois, completamente livre de plantas daninhas até a colheita;

10. Com plantas daninhas durante as 8 primeiras semanas e, depois, completamente livre de plantas daninhas até a colheita.

Em cada parcela foram marcadas 6 plantas dentro das fileiras centrais, onde se realizou a medição por ocasião da colheita. Determinou-se o , stand' final e colheu-se, na área útil, 20 capulhos bem formados, do terço médio das plantas, para posterior análise dos caracteres componentes da produção e das características tecnológicas da fibra.

Foram feitas 2 colheitas entre a segunda quinzena de março e primeira quinzena de maio para o Triângulo Mineiro e entre a primeira quinzena de abril e segunda quinzema de maio para o Norte de Minas.

As precipitações pluviométricas observadas encontram-se no quadro 2.

As espécies que concorreram com a cultura na região do Triângulo, foram as seguintes: Commelina nudiflora L. (trapoeraba), Digitaria sanguinalis (L.) Scop. (capim-colchão), Althernantheraficoidea (L.) R. Br. (apaga-fogo), Sida rhombifolia L. (guanxuma, vassoura), Ipomoea aristolochiaefolia (HBK) Don. (corda-de-viola), Ipomoea cynanchifolia Meissn (corda-de-viola), Amaranthus sp. (carurú-de-porco), Acanthospermum hispidum L. (benzinho), Cenchrus echinatus L. (timbete), Eleusine indica (L.) Gaertn. (capim-pé-degalinha), Richardia sp. (estralador), Borreria sp. (quebra-tijela) e Portulaca oleracea L. )beldroega):

Para a região do Norte de Minas, foram as seguintes: Sida cordifolia L. (vassoura), Sida rhombifolia L. (vassoura), Merremia aegyptia (L.) Urban (jetirana-de-batatal, Ipomoea aristolachiaefolia (HBK) Don. (jetirana), Amaranthus sp. (carurú), Eleusine indica (L.) Gaertn. (capim-pé-degalinha), Cenchrus echinatus L. (timbete), Richardia brasiliensis Gomez (estralador), Hiptis sp. (betônica), Euphorbia pilulifera L. (leiteira), Portulaca oleracea L. (beldroega), Tritachya insularis (L.) Ness. (capim-açú), Centratherium punctatum Cass. (perpétual, Eragrostis sp. (capimfino) e Mimosa sp. (malícia).

\section{RESULTADOS E DISCUSSÃO}

Os dados de rendimento de algodão em caroço podem ser vistos nos quadros 3 e 4 . As análises de variância mostram que houve diferença entre as

Quadro 2 - Resultados das precipitações pluviométricas observadas durante o ciclo da cultura.

\begin{tabular}{|c|c|c|c|c|c|c|c|c|c|}
\hline \multirow{2}{*}{ Localidades e anos } & \multicolumn{8}{|c|}{ MESES $(\mathrm{mm})$} & \multirow{2}{*}{ TOTAL } \\
\hline & Out. & Nov. & Dez. & Jan. & Fev. & Mar. & Abr. & Mai. & \\
\hline \multicolumn{10}{|l|}{ Triângulo Mineiro: } \\
\hline - Capinópolis - 74/75 & 207,0 & 71,5 & 391,9 & 153,0 & 134,3 & 84,4 & 147,7 & - & $1.189,0$ \\
\hline - Capinópolis - 75/76 & - & 27,2 & 184,0 & 16,4 & 152,8 & 114,8 & 34,2 & - & 529,4 \\
\hline - C. Dourada - 75/76 & - & 23,6 & 155,4 & 59,7 & 131,3 & 132,4 & 58,0 & 6,0 & 566,4 \\
\hline - Centralina - 76/77 & 161,0 & 222,5 & 390,5 & 315,5 & 84,0 & 67,5 & 72,0 & - & $1.313,0$ \\
\hline \multicolumn{10}{|l|}{ Norte de Minas: } \\
\hline - Porteirinha - 73/74 & - & 115,8 & 54,4 & 48,6 & 41,3 & 260,0 & 14,8 & - & 534,9 \\
\hline - Porteirinha - 74/75 & - & 194,8 & 163,8 & 105,8 & 84,4 & 36,8 & 164,0 & - & 749,6 \\
\hline - Porteirinha - 75/76 & - & 100,0 & 41,1 & 54,3 & 0,0 & 0,0 & 0,0 & 18,2 & 213,6 \\
\hline - Porteirinha - 76/77 & 66,0 & 167,8 & 156,0 & 176,8 & 122,4 & 139,4 & 31,6 & - & 860,0 \\
\hline - Jafba $\quad-76 / 77$ & 62,4 & 250,0 & 202,5 & 94,8 & 40,3 & 4,0 & 49,3 & - & 703,3 \\
\hline
\end{tabular}


épocas de competição estudadas para as 2 regiões, sendo que o rendimento foi maior, quando se manteve a cultura livre das plantas daninhas, por 6 semanas para o Triângulo Mineiro, obtendo-se $2.254 \mathrm{~kg} / \mathrm{ha}$ e por 8 semanas, para o Norte de Minas, obtendo-se $2.094 \mathrm{~kg} / \mathrm{ha}$. Verificou-se que a partir da quarta semana da emergência, as plantas daninhas não influenciaram no rendimento, para as condições do Triângulo. Já para o Norte, este período de competição foi até a sexta semana (Figura 1 e 2). Podese observar que no Triângulo Mineiro a competição se iniciou mais cedo que no Norte de Minas. As causas dessa diferença podem ser atribuídas à diferente distribuição das chuvas (Quadro 2), diferentes populações de plantas dani nhas e características físicas dos solos.

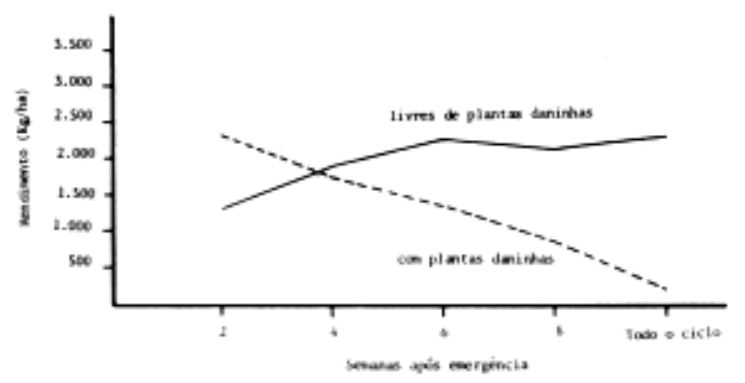

Figura 1 - Período Crítico de Competição de uma Comunidade natural de plantas daninhas e o algodoeiro (G. hirsutum L.), no Triângulo Mineiro nos anos agrícolas de 1974/75, 1975/76 e 1976/77.

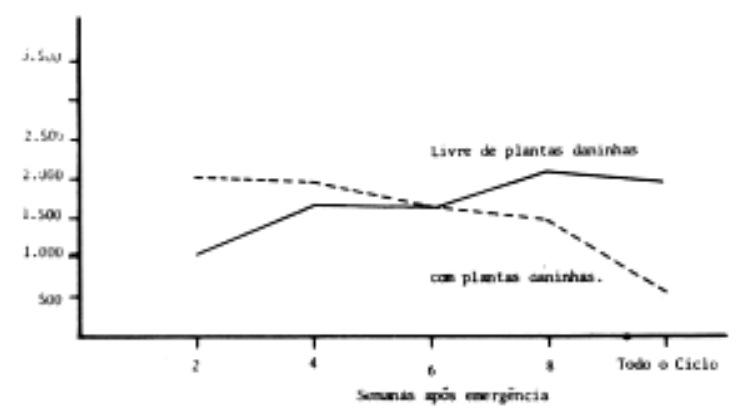

Figura 2 - Período Crítico de Competição de uma Comunidade natural de plantas daninhas e o algodão (G. hirsutum L.), no Norte de Minas, nos anos agrícolas de $1973 / 74, \quad 1974 / 75, \quad 1975 / 76 \quad$ e $1976 / 77$.

Os resultados mostram que a competição total das plantas daninhas no tratamento sem controle, provocou $90,22 \%$ de perdas na produção, no Triângulo Mineiro e para o Norte, foi de $70,73 \%$. Quando as plantas daninhas competiam somente nas 4 primeiras semanas no Triângulo Mineiro, as perdas foram de $23,96 \%$ e para o Norte, quando competiram nas 6 primeiras semanas, as perdas foram de $14,82 \%$ em relação ao tratamento em que as plantas daninhas foram controladas durante todo o ciclo da cultura. Estes resultados concordam com aqueles obtidos por Buchanan \& Burns (3), Campos \& Disu (5). Schawerzel \& Thomas (14), Chaves $(7,8)$, Perdono et al. (11), Buting \& Lea (4). Crowther (9), Cia et al. (6), Blanco \& Oliveira (2) e Beltrão et al. (1).

O número de plantas por parcela na época da colheita diferenciou-se significativamente em ambas as regiões sendo que o tratamento envolvendo competição durante todo o ciclo, foi $\mathrm{o}$ mais afetado (Quadros 3 e 4).

A altura das plantas foi maior quando se deixou a cultura no limpo, sendo que no Triângulo Mineiro foi afetada depois de 4 semanas com competição e sem competição nas 2 primeiras semanas. No Norte o porte diminuiu após 6 semanas com e sem competição. Também a altura do primeiro ramo produtivo, o número de ramos produtivos por planta e o número de capulhos por planta foram maiores com o algodão livre de concorrência das plantas daninhas (Quadro 3 - dados registrados apenas no Triângulo Mineiro).

O peso de cem sementes foi menor no Triângulo, quando se deixou livre de competição somente por 2 semanas e também no tratamento com competição durante todo o ciclo.

Com relação à percentagem de fibra não houve diferenças significativas entre os tratamentos estudados para ambas as regiões. Para o índice de fibras, nas duas regiões, verificou-se que o tratamento com competição durante todo ciclo foi pior que os demais.

Não houve diferença quanto ao comprimento de fibra, uniformidade e indice Presley, sendo que para Micro naire, ocorreu uma distinção entre os tratamentos que sofreram maior competição, porém sem que se diferenciassem dos demais. 
Quadro 3 - Médias dos resultados das caracteristicas económicas e de fibra do algodoeiro no Triângulo Mineiro, nos anos agricolas de 1974/75, 1975/76 e 1976/77, no periodo critico de competiçāo.

\begin{tabular}{|c|c|c|c|c|c|c|c|c|c|c|c|c|c|c|}
\hline TRATAMENTOS & $\begin{array}{l}\text { Plastas } \\
\text { at } \\
\text { Collueits }\end{array}$ & $\begin{array}{l}\text { Alturs } \\
\text { dass } \\
\text { Pantas }\end{array}$ & Rendimento & $\begin{array}{l}\text { Pesso of } \\
\text { um } \\
\text { Capulho }\end{array}$ & $\begin{array}{l}\text { Ramos } \\
\text { Produtivos } \\
\text { por Plannes } \\
\text { (1) }\end{array}$ & $\begin{array}{l}\text { Capulhos } \\
\text { por } \\
\text { Punte }\end{array}$ & $\begin{array}{l}\text { Peos de } \\
100 \\
\text { Sementes }\end{array}$ & Fibra & $\begin{array}{l}\text { Indice } \\
\text { de } \\
\text { Fibras }\end{array}$ & $\begin{array}{l}\text { Altur de } \\
\text { Inserpio } \\
\text { do } 1.0 \text {. } \\
\text { mo Produ- } \\
\text { tivo } \\
\end{array}$ & $\begin{array}{l}\text { Compri- } \\
\text { mento dis } \\
\text { Fibers } \\
\text { SL 2,5\% }\end{array}$ & $\begin{array}{l}\text { Indice de } \\
\text { Unilformi- } \\
\text { dende }\end{array}$ & $\begin{array}{l}\text { Indice } \\
\text { Pressley }\end{array}$ & $\begin{array}{l}\text { Indice Micro- } \\
\text { neive. }\end{array}$ \\
\hline Semanas Liver de Competipio: & $n^{\circ}$ & $\mathrm{cm}$ & $\mathrm{kg} / \mathrm{ha}$ & 8 & n. ${ }^{\circ}$ & $\mathrm{n} .{ }^{\circ}$ & 8 & * & & $\mathrm{cm}$ & $\mathrm{mm}$ & & & \\
\hline $\begin{array}{l}\text { - As primeiras } 2 \\
\text { - As primeiras } 4\end{array}$ & $48.9 \mathrm{z}$ & $110.8 \mathrm{ab}$ & $1306 \mathrm{bc}$ & 5.5 abod & $3.5 \mathrm{ab}$ & $50 \mathrm{ab}$ & $10.6 \mathrm{od}$ & 36.1 & $6.2 \mathrm{at} \times$ & 3000 & 27.8 & 47,4 & 7,7 & $3.8 \mathrm{~b}$ \\
\hline $\begin{array}{l}\text { - As primeiras } 4 \\
\text { - As prt-netras } 6\end{array}$ & 53.72 & $120,6 \mathrm{a}$ & 1895 ab & $5.9 \mathrm{abc}$ & $3.9 \mathrm{ab}$ & 6.22 & 109 bed & 35.5 & $6.1 \times$ & $278 \mathrm{c}$ & 28.5 & 49,1 & 7,8 & $4.0 \mathrm{ab}$ \\
\hline - As prtineiras 6 & 56.62 & 124.8 a & 725446 & 6. $2 \mathrm{ab}$ & 6.02 & $8.5 \mathrm{a}$ & $11.4 \mathrm{abc}$ & 36.0 & $6.6 \mathrm{abc}$ & $273 \mathrm{c}$ & 280 & 48.2 & 7,8 & $4,1 \mathrm{ab}$ \\
\hline $\begin{array}{l}\text {-As primeirzs } 8 \\
\text { Todo o Ciclo }\end{array}$ & $\begin{array}{l}5.31 \\
58.9\end{array}$ & $\begin{array}{l}128,1 \mathrm{a} \\
1269\end{array}$ & $2135 \mathrm{ab}$ & 6,020 & $\begin{array}{c}6,3 \mathrm{a} \\
59 \mathrm{a}, \mathrm{a}\end{array}$ & $9.6 \mathrm{~d}$ & $113 \mathrm{abc}$ & 35.2 & $6.3 \mathrm{abc}$ & $26,4 c$ & 27.7 & 48.2 & 7,7 & $4,0 \mathrm{ab}$ \\
\hline Todo o Ciclo & $35,9$. & $126.9 \mathrm{a}$ & $2300 \mathrm{a}$ & 6.32 & $59 \mathrm{a}$ & $9.5 \mathrm{a}$ & $11.4 \mathrm{abc}$ & 35,7 & $6.6 \mathrm{abc}$ & $26.2 \mathrm{~s}$ & 28,2 & 49.1 & 7.7 & $4,0 \mathrm{ab}$ \\
\hline \multicolumn{15}{|l|}{ Semanas Com Competiçio: } \\
\hline - As primeinas 2 & 57,12 & $126,7 \mathrm{a}$ & 2283 ab & $6.2 \mathrm{ab}$ & $6.3 \mathrm{a}$ & $9,6 \mathrm{a}$ & $11,6 \mathrm{abc}$ & 36.2 & $688 \mathrm{ab}$ & $27.6 \mathrm{c}$ & 280 & 480 & 7,8 & $4,1 \mathrm{ab}$ \\
\hline - As primeiras 4 & $53,9 \mathrm{a}$ & $108.2 \mathrm{abc}$ & $1749 \mathrm{abc}$ & $6.0 \mathrm{ab}$ & $5,3 \mathbf{a}$ & $8.6 \mathrm{a}$ & 11,6 abe & 36.2 & $69 \mathrm{ab}$ & $280 \mathrm{c}$ & 28.4 & 48,6 & 7,4 & $3,9 \mathrm{ab}$ \\
\hline - As primeinas 6 & 49,4 a & $94.6 \mathrm{bcc}$ & $1340 \mathrm{sbe}$ & $6.0 \mathrm{ab}$ & $4,3 \mathrm{a}$ & 7.22 & $12,0 \mathrm{ab}$ & 36.0 & $6.8 \mathrm{ab}$ & $30.1 \mathrm{bc}$ & 28,2 & 47,9 & 7,7 & $4,2 \mathrm{ab}$ \\
\hline - As pnmeiras 8 & 48.1 a & 85,9 od & 846 of & 5,9 abe & $2.7 \mathrm{~b}$ & $4,2 \mathrm{ab}$ & $12,4 \mathrm{a}$ & 35,8 & $7,1=$ & $35,1 \mathrm{ab}$ & 28,6 & 47.8 & 7,7 & 4.32 \\
\hline - Ioso Cieso & $30.1 \mathrm{~b}$ & $70,4 \mathrm{~d}$ & $225 \mathrm{~d}$ & $4.8 \quad d$ & $1.2 \mathrm{~b}$ & $18 \mathrm{~b}$ & $10,1 \quad d$ & 36,0 & $5,8 \quad \mathrm{c}$ & $39,0 \mathrm{a}$ & 27,8 & 47,2 & 7,5 & $3,8 \mathrm{~b}$ \\
\hline Media & 510 & 109.7 & 1633 & 5.9 & 4.6 & 7.0 & 11,4 & 35.9 & 63 & 29,7 & 28.1 & 48,1 & 7,7 & 4,0 \\
\hline Simif. de "F" & $*$ & $*$ & $\ddot{*}$ & 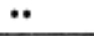 & 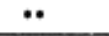 & 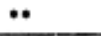 & $\bullet$ & ns. & 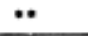 & $*$ & ns. & ns. & n.s. & $\bullet$ \\
\hline C. . 13) & 9.19 & 9.01 & 24,80 & 6,69 & 21,53 & 1893 & 398 & 2.38 & 5,93 & 9,61 & 1,78 & 2,39 & 2.89 & 4.54 \\
\hline
\end{tabular}

OBS : As medias seguidas pela mesme letra. na mesma coluna. nfo diferem niquificatinamente entre si, ao nivel de $5 \%$ pelo teste de Tukey. 
Quadro 4 - Médias dos resultados de caracteristicas econômicas e de fibra do algodoeiro obtidas no Norte de Minas, nos anos agrícolas de 1973/ 74, 1974/75, 1975/76 e 1976/77, no periodo critico de competição.

\begin{tabular}{|c|c|c|c|c|c|c|c|c|c|c|c|}
\hline TRATAMENTOS & $\begin{array}{l}\text { Plantas } \\
\text { na } \\
\text { Colheita }\end{array}$ & $\begin{array}{l}\text { Altura das } \\
\text { Plantas }\end{array}$ & $\begin{array}{l}\text { Rendimen- } \\
\text { to }\end{array}$ & $\begin{array}{l}\text { Peso de } \\
\text { Capulhos }\end{array}$ & $\begin{array}{l}\text { Peso de } \\
100 \\
\text { Sementes }\end{array}$ & $\begin{array}{c}\% \\
\text { de } \\
\text { Fibras }\end{array}$ & $\begin{array}{c}\text { Indice } \\
\text { de } \\
\text { Fibras }\end{array}$ & $\begin{array}{l}\text { Comprim. } \\
\text { Fibras } \\
\text { SL-2,5\% }\end{array}$ & $\begin{array}{l}\text { Indice } \\
\text { de Uni- } \\
\text { formida- } \\
\text { de. }\end{array}$ & $\begin{array}{l}\text { Indice } \\
\text { Pressley }\end{array}$ & $\begin{array}{l}\text { Indice } \\
\text { Micro- } \\
\text { naire. }\end{array}$ \\
\hline Semanas Livres de $C$ & $\mathrm{n}^{0}$ & $\mathrm{~cm}$ & $\mathrm{~kg} / \mathrm{ha}$ & g & $\mathrm{g}$ & $\%$ & & $\mathbf{m m}$ & & & \\
\hline $\begin{array}{l}\text { - As primeiras } 2 \\
\text { - As primeiras } 4 \\
\text { - As primeiras } 6 \\
\text { - As primeiras } 8 \\
\text { Todo o ciclo }\end{array}$ & $\begin{array}{l}51,6 \mathrm{ab} \\
53,7 \mathrm{a} \\
53,7 \mathrm{a} \\
54,2 \mathrm{a} \\
54,0 \mathrm{a}\end{array}$ & $\begin{array}{c}87,6 \mathrm{ab} \\
91,9 \mathrm{ab} \\
94,6 \mathrm{ab} \\
99,7 \mathrm{a} \\
100,6 \mathrm{a}\end{array}$ & $\begin{array}{l}1027 \mathrm{bc} \\
1660 \mathrm{ab} \\
1625 \mathrm{ab} \\
2093 \mathrm{a} \\
1937 \mathrm{a}\end{array}$ & $\begin{array}{l}5,3 \mathrm{ab} \\
5,5 \mathrm{a} \\
5,4 \mathrm{a} \\
5,6 \mathrm{a} \\
5,6 \mathrm{a}\end{array}$ & $\begin{array}{l}10,4 \\
10,7 \\
10,4 \\
10,8 \\
10,7\end{array}$ & $\begin{array}{l}34,6 \\
34,1 \\
34,4 \\
34,4 \\
34,2\end{array}$ & $\begin{array}{l}5,7 \mathrm{ab} \\
5,7 \mathrm{ab} \\
5,7 \mathrm{ab} \\
5,5 \mathrm{ab} \\
5,8 \mathrm{ab}\end{array}$ & $\begin{array}{l}26,6 \\
26,7 \\
26,0 \\
26,4 \\
26,5\end{array}$ & $\begin{array}{l}46,9 \\
46,6 \\
46,7 \\
47,7 \\
47,3\end{array}$ & $\begin{array}{l}7,5 \\
7,5 \\
7,5 \\
7,7 \\
7,6\end{array}$ & $\begin{array}{l}3,9 \\
3,9 \\
3,9 \\
4,0 \\
4,0\end{array}$ \\
\hline $\begin{array}{l}\text { Semanas Com Com } \\
\text { - As primeiras } 2 \\
\text { - As primeiras } 4 \\
\text { - As primeiras } 6 \\
\text { - As primeiras } 8 \\
\text { Todo o ciclo }\end{array}$ & $\begin{array}{l}53,3 \mathrm{ab} \\
53,8 \mathrm{a} \\
53,4 \mathrm{ab} \\
52,7 \mathrm{ab} \\
49,1 \quad \mathrm{~b}\end{array}$ & $\begin{array}{l}97,0 \mathrm{ab} \\
99,7 \mathrm{a} \\
91,2 \mathrm{ab} \\
93,0 \mathrm{ab} \\
82,0 \mathrm{~b}\end{array}$ & $\begin{array}{l}2023 \mathrm{a} \\
1952 \mathrm{a} \\
1650 \mathrm{ab} \\
1456 \mathrm{ab} \\
567 \mathrm{c}\end{array}$ & $\begin{array}{l}5,6 \mathrm{a} \\
5,6 \mathrm{a} \\
5,3 \mathrm{ab} \\
5,4 \mathrm{a} \\
4,6 \mathrm{~b}\end{array}$ & $\begin{array}{l}10,7 \\
10,9 \\
10,8 \\
10,9 \\
10,0\end{array}$ & $\begin{array}{l}34,3 \\
34,1 \\
34,1 \\
34,7 \\
33,4\end{array}$ & $\begin{array}{l}5,7 \mathrm{ab} \\
5,7 \mathrm{ab} \\
5,7 \mathrm{ab} \\
6,0 \mathrm{a} \\
5,3 \mathrm{~b}\end{array}$ & $\begin{array}{l}26,6 \\
26,9 \\
26,9 \\
26,9 \\
26,2\end{array}$ & $\begin{array}{l}47,5 \\
47,7 \\
47,3 \\
48,1 \\
46,9\end{array}$ & $\begin{array}{l}7,9 \\
7,7 \\
7,8 \\
7,9 \\
7,7\end{array}$ & $\begin{array}{r}4,0 \\
4,0 \\
4,0 \\
4,0 \\
3,8\end{array}$ \\
\hline Média & 52,9 & 93,7 & 1599 & 5,4 & 10,6 & 34,2 & 5,6 & 26,6 & 47,3 & 7,7 & 4,0 \\
\hline Sirnif. de "F" & $*$ & $* *$ & $\bullet$ & $* *$ & ns. & n.s. & $*$ & n.s. & n.s. & n.s. & n.s. \\
\hline C.V. (\%) & 3,94 & 7,87 & 26,72 & 5,99 & 3,98 & 2,27 & 4,77 & 2,31 & 1,99 & 3,44 & 4,34 \\
\hline
\end{tabular}

OBS.: As médias seguidas pela mesma letra, na mesma coluna, não diferem significativamente entre si, ao nivel de $5 \%$, pelo teste de Tukey. 


\section{AGRADE CIME NTOS}

Os autores agradecem aos Srs. Luiz Marquez, Walter Alves Ferreira e Seymando Serno Sarmento, por haverem cedido as suas propriedades, Flávio Prates Braga, Gisleno Artur D. Pires, Antônio Melo de Oliveira, José Vicente da Silva, Ernesto Muniz e Orlando Furtado Moreira pela valiosa colaboração na condução deste trabalho.

\section{LIT ERATURA CITADA}

1. Beltrāo, N.E.; Azevedo, D.M.P. \& Lima, R.N.. Competiçáo entre plantas daninhas e o algodoeiro herbáceo (Gossypium hirsutum, raça latifolium L.) nos Estados da Paraiba e Pernambuco. Comunicado técnico n. ${ }^{\circ} 2$. Centro Nacional de Pesquisas do Algodáo - EMBRAPA, 20p. 1978.

2. Blanco, H.G. \& Oliveira, D.A. Contribuição para determinaçáo do período de competição das plantas daninhas na cultura do algodoeiro (Gossypium hirsutum L.). O Biológico, 42: 201205, 1976 .

3. Buchanan, G.A. \& Burns, E.R. Influence of weed competition on cotton. Weed Sci. 18(1): 149-54, 1970.

4. Bunting, A.H. \& Lea, J.D. The ecology and control of weeds at Tozi in East Central Sudan. Emp. J. Exp. Agric. 25: 40-50, 1957.

5. Campos, F.F. \& Disu, M.M. Response of cotton to different duration weed control (variety Deltapine 16). CLSU, Scientific Journal (Philipines). 8(2): 9-12, 1972.

6. Cia, E.; Deuber, R.; Ferraz, C.M.; Sabino, N.P.; Aranha, C.; Leitão Filho, H.R.; Forster, R. \& Veiga, A.A. Competição de plantas daninhas com a cultura do algodoeiro. Bragantia, 37: 53$62,1978$.
7. Chaves, E. Epocas criticas de competición de maleza sobre el algodonero em el Valle del Cauca. In: Seminário de la Sociedad Colombiana de Control de Malezas y Fisiologia.Vegetal (COMALFI), 3.a, Palmira, Colombia, 1971. Resumenes, p.11-12.

8. Chaves, $R$. Competencia de malezas con el algodonero en dos regiones del Cesar (Colombia), Bogotá, Federación Nacional del Algodonero. Departamento Técnico Agricola, 28p. 1972.

9. Crowther, F. Influence of weeds on cotton in the Sudan Gezira. Emp. J. Exp. Agric. 11: 1-14, 1943.

10. Martinez, C.I. \& Nieto, J.H. The critical of competition between seeds and spring cotton in the yaqui valley of Obregon, Sonora, México. Abstr. Weed. Soc. Am., Abstracts, p.1511968.

11. Perdono, A.; Cardenas, J. \& Rojas, E. Épocas críticas de competencia de malezas en algodón en la zona Tolima Sur. In: Seminario de la Sociedad Colombiana de Control de Malezas Y Fisiologia Vegetal (COMALFI), 1. ${ }^{\circ}$, Bogotá, Colombia, 1969. Resumenes, p.50.

12. Ramirez, F.A. \& Nieto, J.H. The critical period - of competition between weeds and winter cotton in the irrigated valley of Mochis, Sins, México, Abstr. Weed. Soc. Am., Abstracts, p. $152,1968$.

13. Rogers, N.K.; Buchanan, G.A. \& Johnson, W.C.. Influence of row spacing on weed competition with cotton. Weed Sci, 24 (4): 410-13, 1976.

14. Schwerzel, P.J. \& Thomas, P.E.L. Weed competition in cotton, Pans, 17(1): 30-4, 1971.

15. Treanor, L.L. \& Andrews, H. Some effects of frequency of cultivation with and without herbicides on corn, cotton and soybeans. Proc. Soc. Weeds. Conf. 18: 49-54, 1965. 